Review

\title{
Microalgae for Biofuels and Animal Feeds
}

\author{
John Benemann \\ MicroBio Engineering, Inc., 3434 Tice Creek Drive No. 1, Walnut Creek, CA 94595, USA; \\ E-Mail: jbenemann@microbioengineering.com; Tel.: +1-925-352-3352
}

Received: 9 September 2013; in revised form: 15 October 2013 / Accepted: 15 October 2013 /

Published: 11 November 2013

\begin{abstract}
The potential of microalgae biomass production for low-cost commodities-biofuels and animal feeds-using sunlight and $\mathrm{CO}_{2}$ is reviewed. Microalgae are currently cultivated in relatively small-scale systems, mainly for high value human nutritional products. For commodities, production costs must be decreased by an order of magnitude, and high productivity algal strains must be developed that can be stably cultivated in large open ponds and harvested by low-cost processes. For animal feeds, the algal biomass must be high in digestible protein and long-chain omega-3 fatty acids that can substitute for fish meal and fish oils. Biofuels will require a high content of vegetable oils (preferably triglycerides), hydrocarbons or fermentable carbohydrates. Many different cultivation systems, algal species, harvesting methods, and biomass processing technologies are being developed worldwide. However, only raceway-type open pond systems are suitable for the production of low-cost commodities.
\end{abstract}

Keywords: microalgae; biofuels; animal feeds; photosynthesis; productivity

\section{Introduction}

This review addresses the autotrophic, that is, using sunlight and $\mathrm{CO}_{2}$, production of microalgae biomass for low-value commodities, specifically biofuels and animal feeds, products with plant-gate value of $\$ 1000 / t$ (metric ton of ash-free dry weight of algal biomass) or less. The development of technologies for microalgae biomass production was initiated sixty years ago at the Massachusetts Institute of Technology in a project to produce the green microalga Chlorella for human foods using enclosed culture systems, so-called photobioreactors (PBRs) [1]. At that time, at the University of California Berkeley, a shallow, mechanically mixed, raceway-type, open pond algae cultivation systems ("high rate ponds" or HRPs) was developed for wastewater treatment, growing mixed 
microalgae cultures [2]. Both systems were subjected to techno-economic analyses (TEA) for food and fuels commodities production, respectively [3,4], with PBRs found to be too expensive.

In the intervening decades considerable progress has been made, for example in the USA by the 1980-1996 Aquatic Species Program [5], and a large world-wide research and development (R\&D) effort is now underway to realize the visions of these early pioneers. However, there is no agreement yet about even such basic issues as the best production technology for microalgae (PBRs or HRPs), the currently or potentially achievable productivities (tons of biomass or liters of biofuels per hectare per year), or the climatic limitations to such processes.

This review addresses these issues and the R\&D needed to achieve the goal of microalgae commodities production. It is based on the author's prior work in this field and his familiarity with the current commercial production of microalgae nutritional products. It does not attempt to review the rapidly expanding recent or even prior publications in this field and, aside some early work, only publications by the author and colleagues are cited. The starting point is an overview of the practical, that is, commercial, experience in microalgae production, as it has developed over the past fifty years.

\section{Commercial Algal Biomass Production}

Microalgae are currently produced commercially mainly for high value $(>\$ 10,000 / t)$ human nutritional products and essentially all ( $>99 \%)$ of the about $15,000 \mathrm{t} / \mathrm{y}$ currently produced are cultivated in open ponds. Raceway-type, paddle wheel mixed ponds (HRPs, Figure 1a-c) are the dominant cultivation system. Almost all Spirulina (Arthrospira), the main type produced commercially, is produced in HRPs, which are also used for Chlorella, Haematococcus and Dunaliella production, the other three microalgae currently produced commercially. These four microalgae and some others of interest in cultivation for fuels and feeds are shown in Figure 2. Circular mixed ponds, developed in Japan in the 1950s [6] are still a major cultivation system used for Chlorella production, almost all in Asia (Figure 1d). Large, up to 100 ha, unmixed ponds are the main system used for Dunaliella cultivation, with about 1000 ha of such production ponds located in Australia (Figure 1e). The only current commercial scale $(\sim 1 \mathrm{ha})$ enclosed PBR system, in Israel, uses tubular reactors to produce Haematococcus (Figure 1f). Another tubular PBR system operates semi-commercially for Chlorella production in a greenhouse in Germany (Figure 1g), and two more such PBRs are to start commercial production in Portugal and Spain in the near future.

Microalgae productivity in raceway ponds is limited to about $3 \mathrm{~g} / \mathrm{m}^{2}-\mathrm{d}$ when supplied only from air $\mathrm{CO}_{2}$ diffusing into the ponds. Thus many commercial operations supply pure $(100 \%) \mathrm{CO}_{2}$, increasing productivities about ten-fold. However, most Spirulina producers in Asia also use bicarbonate as the main source of $\mathrm{CO}_{2}$, and Chlorella producers in Taiwan and Japan add acetate at the end of the cultivation process to boost production. Dunaliella production does not require $\mathrm{CO}_{2}$ fertilization as productivity in the large, unmixed, hypersaline ponds (Figure 1e) is very low. Bubbling air into cultures is another way to deliver $\mathrm{CO}_{2}$, and is practiced in the production of microalgae in bivalve, shrimp and fish hatcheries, but is expensive for large-scale, low-cost algae production [7].

Microalgae ponds are also used in municipal, aquaculture and animal wastewater treatment, but such wastewater treatment ponds are generally unmixed, specific species are not cultivated and the biomass is generally not harvested from such wastewater treatment ponds. 
Figure 1. Commercial microalgae production systems: ponds and photobioreactors. (a-c) Commercial production systems using paddle wheel mixed raceway pond systems. (a) Cyanotech Co., Hawaii, producing Haematococcus pluvialis (red ponds) and Spirulina; (b) Close-up of Cyanotech Spirulina ponds, $\sim 0.3$ ha, note paddlewheels are at far end; (c) Earthrise Nutritionals LLC, California, $\sim 0.4$ and 0.8 hectare ponds, note paddle wheels; (d) Chlorella Industries, Japan, circular ponds, each $\sim 500 \mathrm{~m}^{2}$, with central pivot mixing; (e) Betatene (Cognis), W. Australia, unmixed ponds, Dunaliella production 500 hectares; (f) Algal Technologies, Israel, tubular photobioreactors for astaxanthin production Haematococcus pluvialis; (g) Production of Chlorella in tubular photobioreactors, inside greenhouse, in Germany (facility now owned by Roquette).

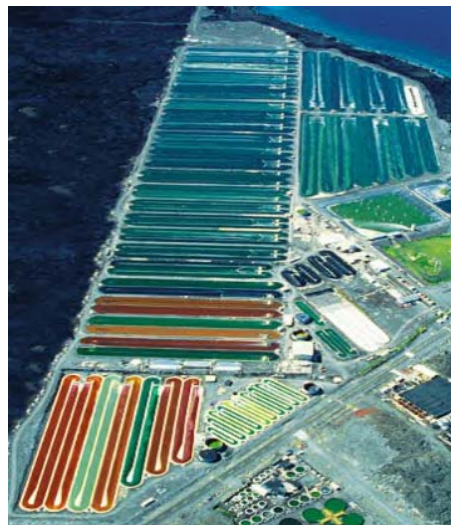

(a)

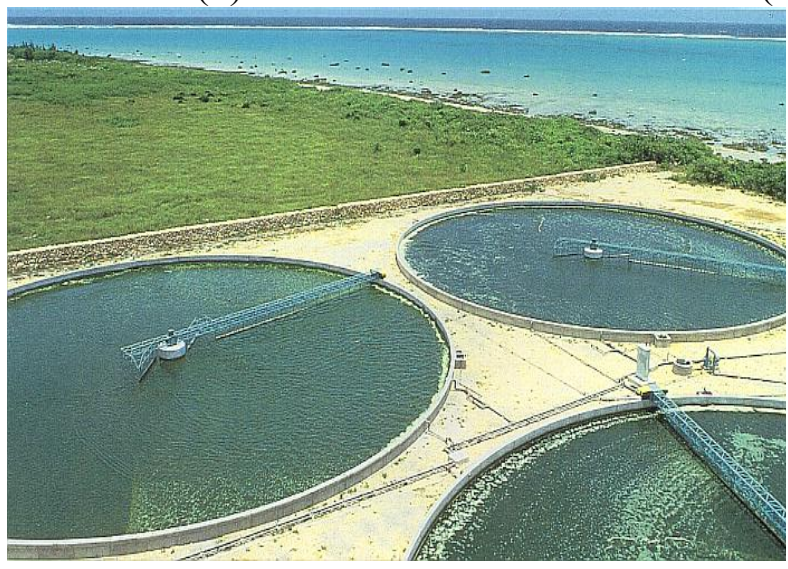

(d)

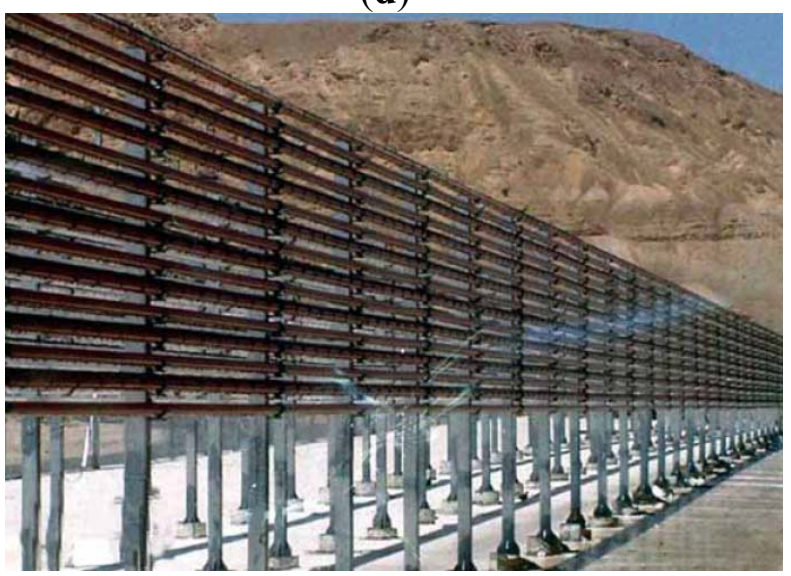

(f)

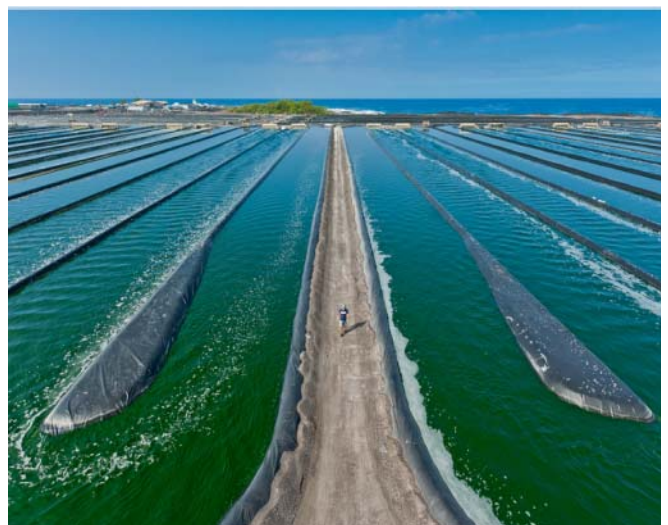

(b)

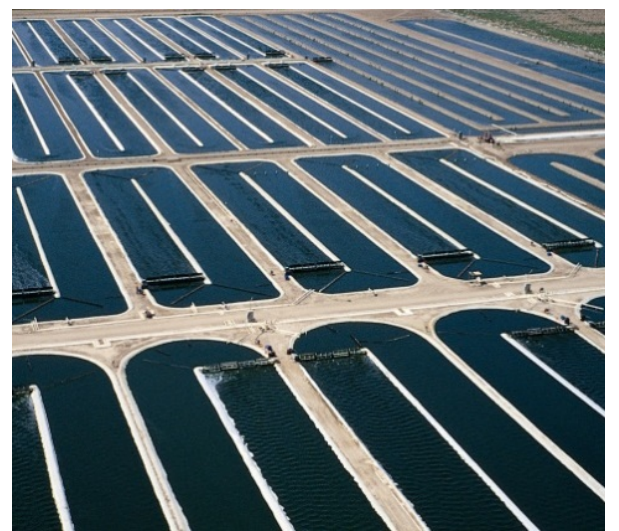

(c)

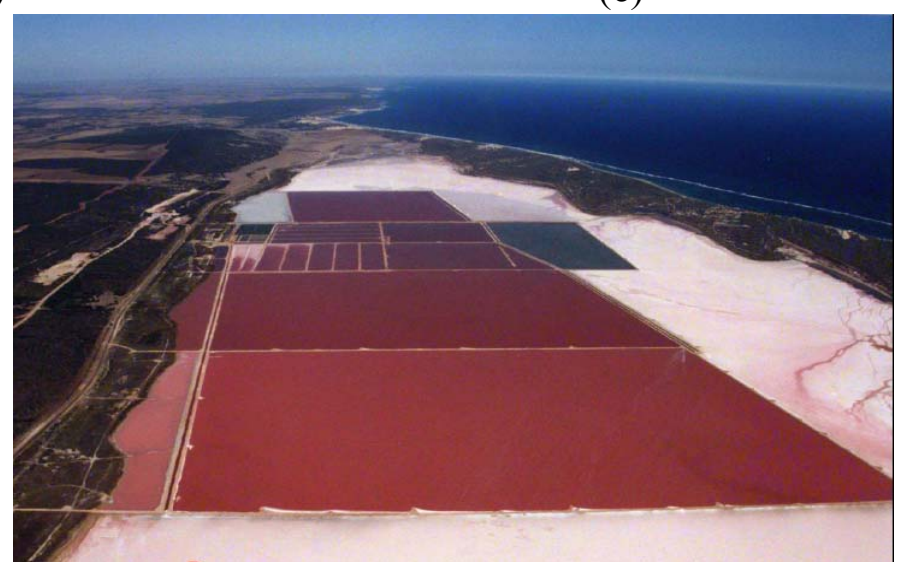

(e)

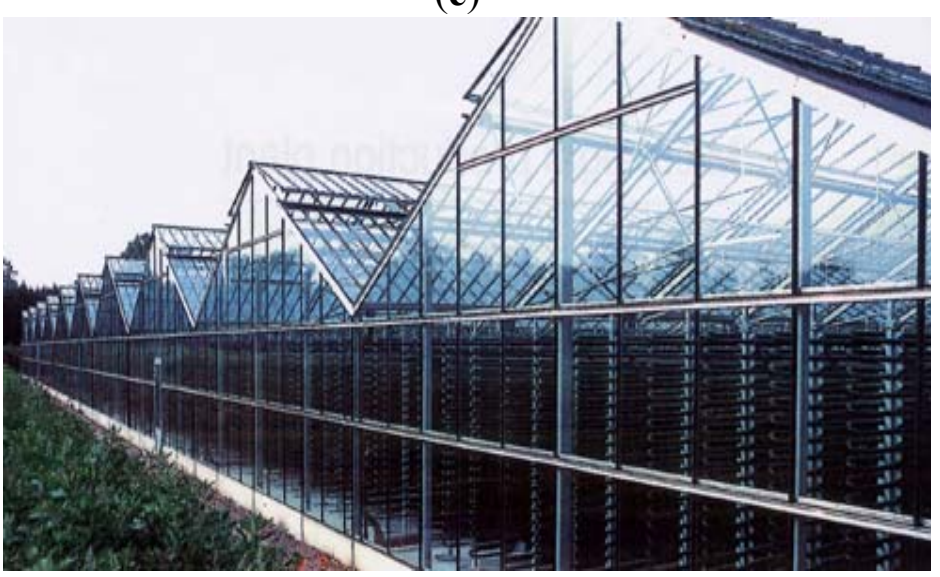

(g) 
Figure 2. Microalgae commercially cultivated and/or of interest in biofuels/feeds production: (a) Arthrospira platensis (Spirulina), is cultured in high alkalinity $(\sim 16 \mathrm{~g} / \mathrm{L}$ bicarbonate) waters; (b) Dunaliella salina grows at high salinity $(>100 \mathrm{~g} / \mathrm{L},>3 \times$ seawater), produces beta-carotene; (c) Haematococcus pluvialis, red color due to astaxanthin, a carotenoid used in aquaculture feeds and nutritional products; (d) Chlorella vulgaris, first microalgae produced commercially for human foods; (e) Amphora sp., as with most diatoms, requires large amounts of silicate, increasing production costs; (f) Nannochloropsis sp., grown in seawater, is now a popular species for biofuel/feed production; (g) Micractinium sp., grown in wastewater, can aggregate into large flocs ("bioflocculation"); (h) Botryococcus braunii, a unique hydrocarbon producing species (see oil droplets release); and (i) Anabaena cylindrica, a nitrogen-fixing cyanobacterium with potential for fertilizer production. Notes: (a-d) currently commercially grown species; (a) and (i) cyanobacteria (also known as blue-green algae); (b-d, g, h) green algae; (e) a diatom; and (f) a Eustigmatophyte; (b, e, f) saltwater; and $(\mathbf{c}, \mathbf{d}, \mathbf{g}-\mathbf{i})$ freshwater or brackish water microalgae.

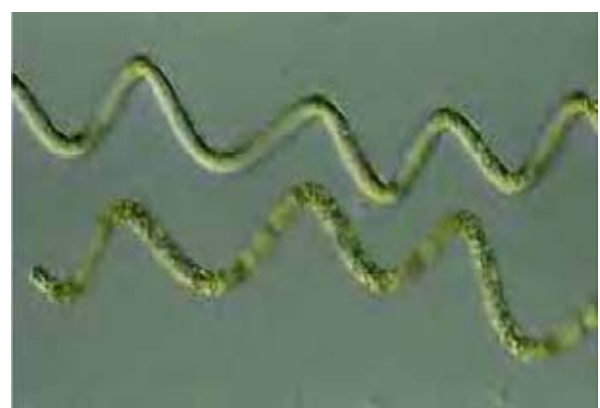

(a)

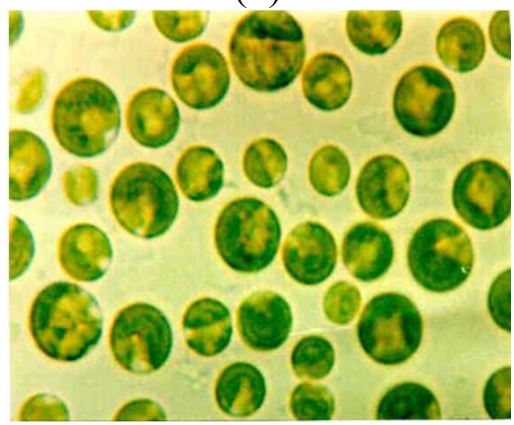

(d)

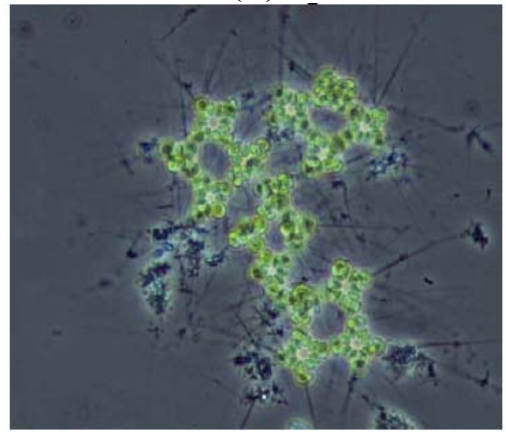

$(\mathbf{g})$

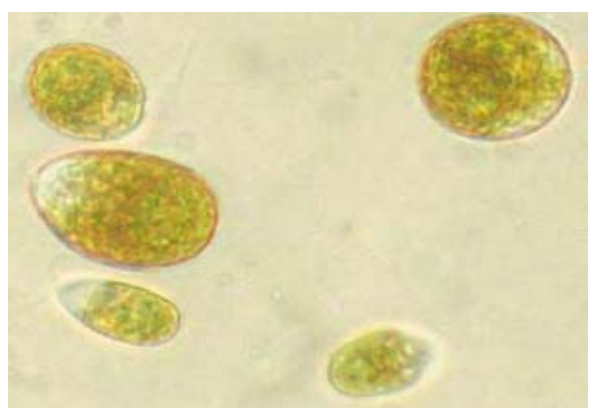

(b)

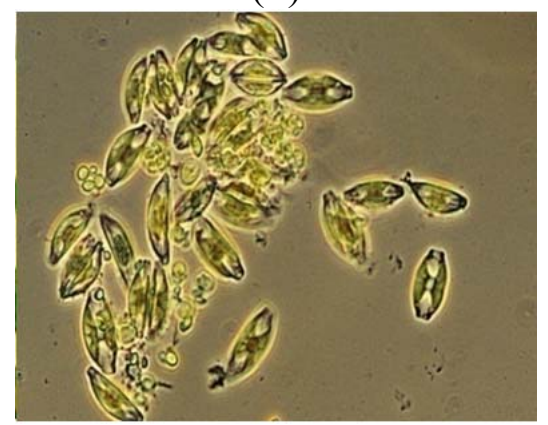

(e)

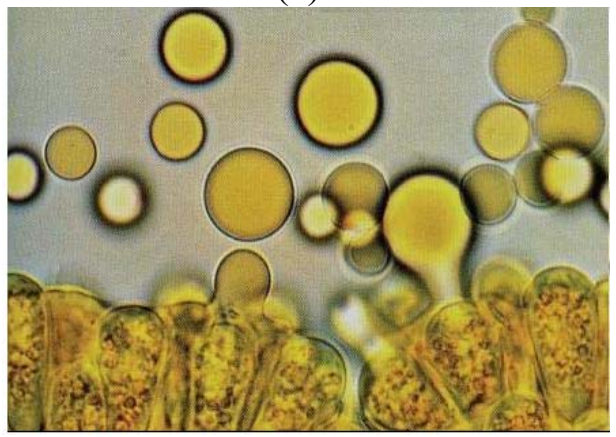

(h)

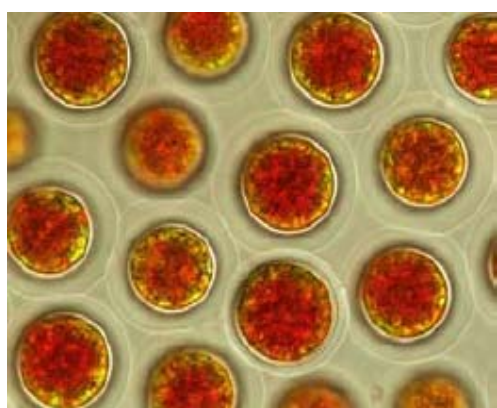

(c)

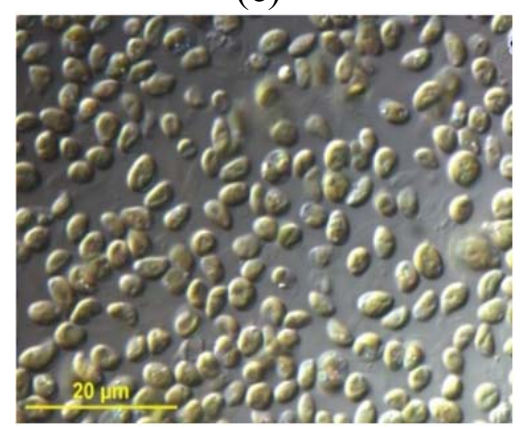

(f)

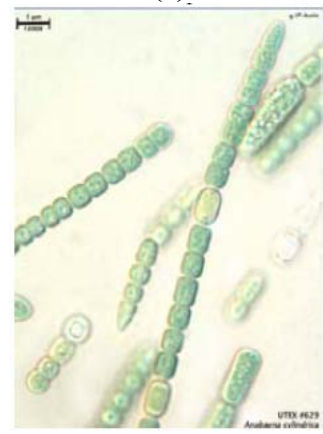

(i)

No reliable information on commercial production of microalgae has been published, and only very approximate estimates of production volumes and plant gate costs for bulk biomass are possible: roughly $10,000 \mathrm{t} / \mathrm{y}$ and $\$ 10,000 / \mathrm{t}$ for Spirulina, $4000 \mathrm{t} / \mathrm{y}$ and $\$ 20,000 / \mathrm{t}$ for Chlorella, $1000 \mathrm{t} / \mathrm{y}$ and 
$\$ 20,000 / \mathrm{t}$ for Dunaliella, and $200 \mathrm{t} / \mathrm{y}$ and $\$ 100,000 / \mathrm{t}$ for Haematococcus. These estimates are for direct production costs for dry weight, but otherwise not further processed algal biomass, and they do not include corporate, marketing, and other such indirect cost. Also, production costs vary greatly among plants, locations and production systems. For example, Chlorella or Haematococcus biomass produced in PBRs is several-fold more costly to produce than the same algae cultivated in open ponds. Processing of the biomass, such as extraction of astaxanthin from Haematococcus or of beta-carotene from Dunaliella, adds to product costs. Finally the value-added through formulations, packaging, distribution, marketing, etc., increases the market value of microalgae products by over an order of magnitude, making their production a multi-billion dollar global industry.

However, commodities - feeds, fuels and chemicals, including bioplastics - by microalgae are currently not produced commercially, and require production costs to be reduced by well over an order of magnitude and volumes to be increased many hundred-fold. This is the challenge addressed herein.

\section{Microalgae R\&D for Biofuels and Other Commodities}

In the past five years, there has been an explosion of interest in microalgae for biofuels, and, to smaller extent, for animal feeds, with, so far, relatively little focus on bio-based chemicals, plastics or polymers (not further specifically discussed herein). During the past few years roughly a billion dollars have been invested annually in this field, from public and private sources, with about ten thousand scientists and engineers now directly employed in such R\&D projects, working in academic and government laboratories and private enterprises. Hundreds of reviews, analyses and laboratory studies on microalgae biofuels and related topics are being published annually and large numbers of patents are being filed.

Publicity releases routinely announce the imminent commercial production of algal biofuels, starting in the next year or two, or sooner, but that is unlikely. The technology for commercial production of microalgae for high value products by private enterprises, reviewed above, generally required over a decade to develop and another decade to achieve profitability. The challenges of algal biomass production for commodities are much greater than those faced in the development of these higher value products, and it is not plausible that the recently formed ventures or government-funded $R \& D$ projects will succeed in short order in the commercial production of microalgae commodities.

Most of the research in this field has focused on liquid biofuels, mostly on the production of vegetable oils (triglycerides) for conversion to biodiesel. Vegetable oils and other algal lipids can also be converted into conventional hydrocarbon fuels, including aviation fuels, using available refinery technologies. The direct production of hydrocarbons by microalgae, specifically by Botryococcus braunii (Figure 2h), has also received attention, as have ethanol and other liquid fuels. Methane (biogas) production was the first biofuel from microalgae proposed and already studied in the 1950s [8]. Hydrogen gas evolution by microalgae was first reported in the 1940s [9], and $\mathrm{H}_{2}$ fuel production has been the subject of extensive R\&D starting forty years ago [10], and continues to be an active field of research, though with no prospects of practical applications in the foreseeable future [11].

More recently, much attention has been focused on hydrothermal liquefaction (HTL) technologies, in which freshly harvested, but not dried, algal biomass (from 5\% to $20 \%$ solids, that is $80 \%-95 \%$ moisture) is pressure cooked at $300-350{ }^{\circ} \mathrm{C}$ (up to 200 atmosphere pressures, at near-supercritical 
water conditions). HTL produces pyrolysis-type bio-oil that can be upgraded to conventional fuels. However, actual fuel yields, quality and costs, of HTL processes remain to be determined.

Biofuels production in combination with animals feeds production, wastewater treatment or higher value co-products (the "biorefinery" concept) have been proposed as a way to overcome the economic limitations of biofuel-only processes. These topics are, briefly, addressed herein; however the focus is on microalgae biomass production, rather than specific biofuel conversion technologies.

Microalgae are currently also produced commercially by dark fermentations (heterotrophically, using starch or sugars), at roughly the same scale as autotrophic production, and this is also a rapidly expanding industry. The main production is in the Far East for Chlorella and in the USA, for algal oils (triglycerides) high in the omega-3 fatty acid DHA (docosahexaenoic acid), used mainly as an ingredient in infant formulas. Dark fermentation processes also are being proposed to produce biofuels, commodity feeds and specialty chemicals, however these technologies are not further discussed herein. Neither is the much larger category of macroalgae (seaweeds), a topic somewhat neglected in the biofuels/feeds space (see [12] for a review).

\section{Low Cost Algae Cultivation Systems}

For commodities the costs of production, both capital and operating, must be very low. As mentioned earlier, autotrophic microalgae cultivation can be carried out in open or covered raceway ponds (HRPs), or in closed photobioreactors (PBRs). The latter include tubular, bag, flat plate, conical, spherical, and many other designs, in many configurations - horizontal, inclined, helical, vertical, rotating, submerged, floating, etc. Due to gas exchange limitations $\left(\mathrm{CO}_{2}\right.$ supply to the algae and $\mathrm{O}_{2}$ removal), individual PBRs cannot be scaled much above about $100 \mathrm{~m}^{2}$, whereas single open raceway ponds can be well over one hectare $\left(>10,000 \mathrm{~m}^{2}\right)$ in size [13]. Production of commodities will require hundreds of hectares for commercial-scale systems, thus tens of thousands of individual PBR units, compared to a few score multi-hectare raceways ponds (HRPs). High capital and operating costs of PBRs, due to their small unit scales and large material investments, excludes them from consideration in commodities production. Some PBRs will be needed for production of seed (inoculum) cultures, but at only about $\sim 0.1 \%$ of the area of the associated production ponds. Thus, the PBRs would represent only a minor cost for the overall process.

In brief, PBRs are between one to two orders of magnitude more costly, capital and operating, than HPRs and also present major design and operating challenges (gas exchange, overheating, fouling/cleaning, etc.) Despite this, many, perhaps most, researchers working on algae biofuels and feeds work with PBRs instead of open ponds. PBRs are viewed as more productive, more controllable, less subject to contamination, consuming less water, and achieving higher cell densities - all these advantages supposedly making up for their higher costs. Except for higher cell densities, and thus lower harvesting costs, these claims have little basis in fact or experience (see further discussion below). Even covered ponds are not affordable for algal biofuels or feeds production, just as greenhouse agriculture is only economically feasible for very high value crops-flowers, out-of-season fruits, etc. Some covered ponds would be used in inoculum production, following the initial smaller inoculum PBRs, but at $\sim 1 \%$ of total area, their overall costs can be neglected. 
These considerations leave open ponds as the only potentially practical systems for microalgae commodities production. Large commercial algal pond systems, about 500 hectares, are used for cultivation of Dunaliella (Figure 1e). Although of very low cost, these also exhibit very low productivities, less than a tenth that of high rate (e.g., raceway, mechanically mixed) ponds (HRPs). The low productivities of the Dunaliella ponds is mainly due to the very high salinities $(>150 \mathrm{~g} / \mathrm{L})$ at which these microalgae grow, conditions required to produce high levels of beta-carotene. Circular mixed ponds (Figure 1d) are limited to about 0.1 ha, mainly because mixing is not scalable. Thus, only HRPs, first studied by Oswald and colleagues at the University of California Berkeley [2], developed further since [14-16], and currently used in the cultivation of Spirulina (Figure 1a-c), the other microalgae produced commercially, and in wastewater treatment, can be considered for low-cost microalgae production. For low cost commodities production, individual pond sizes must be as large as possible, several hectares, and lined with compacted clay, as plastic liners are at present too expensive. Further, as discussed next, engineering and economics limit pond depth to $\sim 30 \mathrm{~cm}$, mixing velocity to about $20-25 \mathrm{~cm} / \mathrm{s}$, $\mathrm{pH}$ from about 7.5 to 8.5 , and harvest rate (dilution) from $20 \%$ to $40 \%$ per day [13].

\section{Raceway Ponds for Microalgae Cultivation}

Mixing of HRPs is required to maintain a uniform algal culture and supply it with nutrients, most critically $\mathrm{CO}_{2}$. $\mathrm{CO}_{2}$ cannot be distributed over the entire pond surface, but must be injected at as few locations as possible, preferably only one, to reduce the cost of distribution piping to a minimum. $\mathrm{CO}_{2}$ injection requires a diffuser in a sump, controlled by a $\mathrm{pH}$ sensor, to deliver $\mathrm{CO}_{2}$ to the algal culture as demanded by algal photosynthesis (which raises culture $\mathrm{pH}$ as it uses $\mathrm{CO}_{2}$ and bicarbonate). The alternative, delivering the algae culture to a central $\mathrm{CO}_{2}$ supply station, is not practical. The number and spacing of the sumps is a major capital and operating cost factor and depends on many factors - pond depth, alkalinity, $\mathrm{pH}$ set points, maximal hourly rate of photosynthesis, temperature, and mixing velocity. Power consumption for mixing increases as a cube function of water velocity from 20 to $25 \mathrm{~cm} / \mathrm{s}$ about the maximum affordable for commodities production. This mixing velocity is also near the likely minimum, as other critical factors are also affected by mixing speed, such as outgassing of $\mathrm{O}_{2}$ and $\mathrm{CO}_{2}$, silt suspension, and algae settling [13].

Plastic liners could allow cleaning the ponds to reduce contamination by unwanted algal strains, grazers and diseases. However, liners are expensive and cleaning hundreds of hectares of ponds is not practical. Thus, only a small portion, at most $5 \%$ to $10 \%$, of a large pond system could be affordably lined with plastic and occasionally cleaned. This area would be used to produce large amounts of seed culture, starting with PBRs, then covered ponds, and finally plastic lined ponds of increasing size [17]. This process of inoculation needs to be demonstrated in practice, though no practical alternative is apparent. Ponds not lined with plastic would need to be clay lined, either native or imported from nearby, to limit percolation. Lining, sealing, percolation, and cleaning of ponds are all important issues in the design and operation of large-scale microalgal production systems, and practical experience is presently limited to smaller-scale, plastic lined ponds used for higher value products. The major issue is the ability to grow selected strains of algae in such large, dirt bottom, open ponds that are not cleaned, as discussed further below. 
Although paddle wheels, due to their flexibility, are the most prevalent, almost exclusive, mixing system for raceway ponds in commercial use, alternative mixing devices - jet mixers, pumps, airlifts, mixing boards, gravity flow, etc.- have all attracted interest. However, these do not appear to have major capital or operating cost advantages, such as greatly reduced energy inputs, which are determined primarily by the horizontal flow velocity in the raceways, and which should be maintained, as just noted above, in the range of 20 to $25 \mathrm{~cm} / \mathrm{s}$.

Another issue is the source of $\mathrm{CO}_{2}$ : either pure $100 \% \mathrm{CO}_{2}$ or dilute flue gas $\left(\sim 10 \% \mathrm{CO}_{2}\right)$ from power plants or other stationary sources. Pure $\mathrm{CO}_{2}$ is more expensive, but cheaper to pipe to and transfer into the ponds, than flue gas $\mathrm{CO}_{2}$. Piping of flue gas $\mathrm{CO}_{2}$ from power plants or similar sources to algae ponds would be limited by both capital and operating costs to a few kilometers. Further, a $\mathrm{CO}_{2}$ content of much below $10 \%$ in the flue gas may not be economically feasible for large-scale microalgae production. In brief, the design and operation of low-cost algal production systems is severely constrained by several fundamental factors, including the need to provide $\mathrm{CO}_{2}$ to the algal cultures. More detailed site and case-specific studies are required.

\section{Stability of Microalgae Cultivation}

As noted above, the present experience with commercial cultivation of microalgae is limited to four algae genera, all of which exhibit rather modest productivities and high costs. Reducing current costs by over an order of magnitude is required for production of commodities, biofuels and feeds, a daunting goal, though no insurmountable barriers are apparent that make this an implausible objective. The above outlined constraints on engineering designs as well as the local environment (climate, water source, etc.) determine the parameters within which the algal cultures must operate: $\mathrm{CO}_{2} / \mathrm{pH}$ and $\mathrm{O}_{2}$ concentrations, salinity, mixing regime, pond temperature, and solar insolation. Further, harvesting of the algae biomass must use very low-cost processes (discussed below), and the biomass must be of desired composition (e.g., high oil content, good feed value, etc.) Algal strains thus need to be selected and genetically improved to exhibit all the required characteristics, perhaps the most important ones being stable cultivation and high biomass productivity.

The first requirement, the stability of the algal cultures, means that they must withstand invasion by other algal species, decimation by grazers, fungal and viral infections, in brief all types of pests and diseases. Without the management of such biotic challenges, all other issues become moot. Current commercial experience provides some, though only modest, assurance that this is possible: Spirulina and Dunaliella are cultivated, respectively, in high bicarbonate $(16 \mathrm{~g} / \mathrm{L})$ or high salinity $(>100 \mathrm{~g} / \mathrm{L})$ media, providing conditions that greatly reduce biotic invasions and allow relatively stable cultivation, but at low productivity. Freshwater Haematococcus and Chlorella require frequent culture re-starts, pond cleaning, and production of large amounts of inoculum under controlled conditions, and also have relatively low biomass productivities. However, little is known about the details of such commercial operations. Further, biotic challenges change constantly and control techniques applicable one month or year may not apply the following. Control using chemicals (ammonia, chlorination, acidification, surfactants, etc.) or specific herbicides, fungicides, etc., is only partially effective and limited by costs, as would frequent culture re-starts. A combination of techniques, including biological controls, crop rotations and even pond fallows, as used in agriculture, will likely 
be required to manage, though not prevent, invasions and infections. The long-term cultivation of several Nannochloropsis species has been demonstrated in outdoor raceway ponds and commercial-scale production of several species of this microalga is being initiated for nutritional products and aquaculture feeds in China, Australia, USA, and elsewhere. Other promising candidates for mass culture are Tetraselmis, Cyclotella and Scenedesmus, to mention just three genera for which longer-term open cultivation has been reported. Thus, large-scale production of new genera and strains, beyond those commercially produced, appears feasible. However, little information is available on the invasions of such cultures by other algae or of pond "crashes" caused by grazers, fungal infections, etc. The development of algal strains, cultivation and "crop protection" technologies that allow stable cultivation in large production ponds must be a starting point for any R\&D effort in microalgae commodities production. In brief, culture stability is central to the production of algal commodities. However, this is only a starting point for the development of the required algal strains. The next challenge would be how to increase productivity.

\section{Photosynthesis and Microalgae Productivity}

The fundamental and practical limits of photosynthesis, and thus biomass productivity, are due to:

(i) the minimum number of photons, $\sim 10$, needed to reduce one molecule of $\mathrm{CO}_{2}$ to carbohydrates;

(ii) only $\sim 45 \%$ of solar photons, roughly the visible light spectrum, being used in photosynthesis;

(iii) light saturation and photoinhibition, due to the high content of light absorbing pigments; and;

(iv) reflection, inactive absorption, respiration, high $\mathrm{O}_{2}$ levels and other non-optimal conditions.

From (i) it can be calculated that at most $22 \%$ of the energy in the photon captured by and used in photosynthesis can be transformed into biomass energy. This, multiplied by (ii), translates into a $10 \%$ maximum possible total solar energy converted into biomass by photosynthesis. However, (iii), light saturation and photoinhibition, reduce this efficiency by another at least $70 \%$. Light saturation is the effect that the rate of photosynthesis by algal cells does not increase above a light intensity of about one-tenth of full sunlight. Light saturation occurs because individual algal cells have a high content of so-called "light harvesting" pigments (chlorophyll in green algae, phycobiliproteins in cyanobacteria, or fucoxanthin in diatoms). This high content of such pigments results in more photons, about ten-times more, being absorbed at full sunlight than the photosynthetic apparatus can actually utilize. Photosynthesis by individual algal cells thus does not increase above $\sim 10 \%$ of full sunlight: light intensity above this level results in photons being absorbed that cannot be used to fix $\mathrm{CO}_{2}$ and produce biomass. The excess photon energy is lost, as heat or fluorescence, and in the process also damaging the photosynthetic apparatus: photoinhibition. Factoring in the light attenuation by a dense algal culture (where most algal cells are always at relatively low light intensity), overall solar efficiency is reduced by the above stated about $70 \%$. This results in an overall maximum efficiency of $\sim 3 \%$ of total solar energy converted into algal biomass. Further, unavoidable practical losses, listed in (iv) above, will reduce total solar energy conversion efficiency by another at least third to half. Thus $1.5 \%-2 \%$ is the highest solar conversion efficiency that can be projected at present, and is observed in experimental pond cultures. Assuming a favorable location (e.g., southwestern USA) with an solar insolation of $7 \mathrm{GJ} / \mathrm{m}^{2}-\mathrm{y}$, and a $20 \%$ algal oil (triglycerides) content, this translates into 
45 to 60 t/ha-y algal biomass (organic dry weight, @ 23 GJ/t, higher heating value), or about 10,000 to 13,500 liters algal oil/ha-y. This is an upper range for any current productivity projections, using natural algal strains. If achievable, this would be up to twice that of palm oil, the most productive current oil crop.

However, most techno-economic analyses (TEAs, see further discussion below) conclude that even higher productivities will be required for the production of algae production to be economically competitive with other biofuels or animal feeds. The only plausible approach to achieve a major increase in productivities is to overcome the above described light saturation and associated photoinhibition effects. There are several, at least at first glance three apparently approaches to achieving this goal: light dilution, flashing lights, and reduction of the light harvesting pigments.

Light dilution, can be achieved by vertical orientation of PBRs (Figure 1f,g), thus distributing the direct sunlight intensity received by the algal cultures over a larger area and thus increasing photosynthetic efficiency. However, in practice, vertical PBRs can at best achieve only about a 50\% increase in productivity per area (e.g., per $\mathrm{m}^{2}$ ) of ground occupied, compared to horizontal PBRs or ponds. However, this would require at least three $\mathrm{m}^{2}$ of PBRs per $\mathrm{m}^{2}$ of ground area. Doing the math: $1.5 \times$ productivity $/ 3 \times \mathrm{PBR}$ area $=0.5 \times$ productivity $/ \mathrm{m}^{2}$ of PBR. As PBRs cost well over ten-times the ground they sit on, this is a poor trade-off, even for this best-case scenario. An even more negative evaluation applies to light dilution schemes with concentrating mirrors coupled to optical fibers, or the use of prisms inserted in the algal culture, approaches that also have attracted many researchers and even private companies. In brief, light dilution is not a practical method for increasing microalgae culture productivities.

Productivity can also be increased by the so-called "flashing light" effect: a few microseconds burst of very bright light (e.g., full sunlight intensity), followed by a dark period about five times longer, increases photon conversion efficiencies in dense cultures by about three- to four-fold [18]. The short pulse of high light allows the photosynthetic apparatus in the algal cells to absorb the maximum number of photons that it can process in the following dark period, thus increasing efficiency to near maximal. However, such short time periods cannot be achieved in scale-up — at best some modest effect may be observed in highly mixed PBRs, but requiring a very high energy input. Thus, rapid mixing to increase productivity is impractical and can also be dismissed from consideration.

This leaves the third approach: reducing the amount of light harvesting pigments in the algae [19]. Finding natural strains with reduced light harvesting pigment content, that is small antenna sizes, is highly unlikely as such strains have a competitive disadvantage at low light intensities, the situation in which algal cells find themselves most often in any natural environments. Thus the development of algal strains with a reduced amount light harvesting pigments was suggested [20]. An early demonstration of this approach came from the study of environmentally stressed algal cultures with low rates of photosynthesis and low chlorophyll content, which when transferred to normal growth conditions exhibited increased photosynthetic rates at high light intensities [21,22]. Mutants with reduced antenna size also have been shown to have a higher light saturation level at high light intensities [23-26], but these were laboratory results that cannot be extrapolated to mass culture conditions. Demonstration of sustained productivity increases in outdoor ponds under full sunlight, using algal strains with reduced light harvesting pigments, is still lacking. However, it can be anticipated that the currently ongoing world-wide R\&D effort to develop such strains will soon be 
successful and that the above current projected maximum total solar conversion efficiency could be doubled to $3 \%$ to $4 \%$, yielding a biomass productivity of about, $100 \mathrm{t} / \mathrm{ha}-\mathrm{y}$ and an oil production of 20,000 to $25,000 \mathrm{~L} / \mathrm{ha}-\mathrm{y}$. It may be possible to further increase, using genetic methods, the a recoverable oil content in algae of plausibly to a third of the biomass, yielding up to 40,000 L/ha-y. Such high oil content has, thus far, been achieved only with $\mathrm{N}$ limited growth arrested algal cultures (as first studied during World War II [27]).

In conclusion, achieving simultaneously both a high oil content and a high solar conversion efficiency is the central goal for microalgae biofuels production. This achievement will require genetic improvements that both greatly reduce the light harvesting pigments and also re-direct at least half of the $\mathrm{CO}_{2}$ fixation products into triglycerides production. Projections much above 40,000 L/ha-y for biofuels, or about $100 \mathrm{t} / \mathrm{ha}-\mathrm{y}$ for animal feeds, as all too often projected by promoters in this field, are unrealistic, even in the long-term. However, these are not the only requirement for commodities production, as discussed next.

\section{Cultivation, Harvesting and Processing}

Algal production cultures must be supplied with all required nutrients $\left(\mathrm{CO}_{2}, \mathrm{~N}, \mathrm{P}, \mathrm{K}, \mathrm{Ca}, \mathrm{Mg}\right.$, etc.), but only as much as needed for algal growth, to avoid any excess being present in the medium. On average about $20 \%$ to $40 \%$ of the pond volume is harvested daily, the fraction depending on algal growth, in turn determined mainly by temperature, sunlight and algal strain. Harvesting of the dilute algal cultures (a few hundred mg per liter) present in such ponds requires an initial $\sim 100$-fold concentration, to $2 \%-4 \%$ solids. However, centrifugation, chemical flocculation or membrane filtration, the main commercially available processes, are too costly for commodities. "Bioflocculation", the settling of the algal cells using little or no chemical flocculants, is a sufficiently low-cost approach for commodities production, but depends on strain and growth conditions $[15,16]$. A related process, applicable in some cases, is the co-flocculation of algae with $\mathrm{Ca}$ and $\mathrm{Mg}$ ions in the growth medium at high $\mathrm{pH}$ ("autoflocculation"), a result of photosynthesis in the absence of a $\mathrm{CO}_{2}$ supply. These methods still need to be perfected and demonstrated for each algal strain and cultivation regime. Alternative low-cost harvesting processes may be possible; many have been proposed, and this is a fertile area for R\&D. After initial harvest, the biomass slurry must then be concentrated to $10 \%-20 \%$ solids, as needed for further processing. Centrifugation or membrane filtration is affordable above about a $2 \%$ solids concentration.

After initial harvesting and concentration, the supernatant water must be largely recycled to the growth ponds, another process for which only limited data are available. The concentrated biomass would then be subjected to cell breakage and/or drying (spray or sun drying, etc.) and further processing (e.g., oil extraction, etc.). Cell breakage of wet biomass and oil extraction by centrifugation was proposed as a relatively simple and low cost process that does not require drying, but still must be demonstrated in practice [17]. Cell breakage will also be required for making the algal biomass digestible for use as animal feeds. Cell breakage methods (autoclaving, high pressure homogenization, sonication, enzymatic lysis, ball milling, etc.) need to be developed for each algal strain and application. Converting the algal oil into useful biofuels (biodiesel, "green diesel", jet fuel, etc.) further adds to costs, but can be based on existing processes (e.g., transesterification for biodiesel production). 
In processes where algal oil is used to produce biofuels, the residual biomass would be converted by anaerobic digestion to biogas, for electricity generation. The flue gas and digester residues would be recycled to the ponds, to recover nutrients and carbon, a process first proposed by Oswald and Golueke over 50 years ago [3]. The electricity could provide most process energy needs, even generate a surplus, improving the environmental benefits of this technology (see below). It is often proposed to use the residual biomass after oil extraction as an animal feed (the "biorefinery" concept). However, it is more plausible that, if animal feeds are the objective, the entire algal biomass would be used for animal feed. This would generally require drying, and likely also cell breakage. In conclusion, thus far, low-cost algae harvesting is currently a key limiting factor in the production of microalgal commodities. A universal low-cost harvesting technology, applicable to all algal species, is unlikely and algal harvesting R\&D must be integrated with cultivation processes. Processing (cell breakage, drying, oil extraction) also requires $\mathrm{R} \& \mathrm{D}$, but appear to be lesser problem. The biorefinery concept, in which higher value products are co-produced with biofuels or animal feeds, is, however, not applicable to algal commodities production. Neither is the co-production of feeds and fuels with higher value products, as the latter have much too small markets to justify such a process.

\section{Resource Potential and Limitations}

Brackish inland water sources, not useful in agriculture, were considered for microalgae biofuels production by the US Aquatic Species Program [4], which, as noted in the introduction, was a precursor to many of the now ongoing worldwide activities in this field. However, in most cases brackish waters are mined from deep groundwaters and are available only in limited or often unknown quantities. Also a large fraction would need to be discharged or re-injected (as a "blow-down") after each harvest to manage pond salinity. In humid areas, fresh water is often more available, but these are generally not the most favorable locations for algae production, due to greater cloud cover and higher pond temperatures (due to limited evaporative cooling). Municipal and agricultural wastewaters can be used to cultivate microalgae for biofuels, but are also limited resources. The most promising water resource for microalgae commodities production is seawater. Seawater sources are restricted to coastal areas of modest elevation, where the pumping required would not be prohibitive. In brief, water resources will limit algae feed and fuel production.

As noted above, microalgae, unlike conventional crops, require enriched $\mathrm{CO}_{2}$ sources. Although enormous amounts of $\mathrm{CO}_{2}$ are dumped into the atmosphere from the combustion of fossil fuels, its suitability, availability and transport makes $\mathrm{CO}_{2}$ the main limiting factor in algal production, even more so than water resources. Because of diel and seasonal limitations, the actual fraction of $\mathrm{CO}_{2}$ captured from a large conventional power plant is at most a third of the total [17]. If practical limitations to flue gas transport are considered, a $2 \%-3 \%$ utilization would appear to be an upper limit, and that only in locations with sufficiently available water and land resources for such a process.

It is the juxtaposition of all the requirements for algae mass cultivation - climate, land, water and $\mathrm{CO}_{2}$ - that restricts the overall potential of this technology, as already recognized long ago [14]. For example, the relatively high capital costs of algal production systems, compared to conventional agriculture, requires a long growing season, making northerly latitudes unsuitable. Even without detailed, site specific, studies, the enormous resource potential projected by many 
proponents of microalgae technologies are not realistic. The global resource potential for microalgae commodities production is plausibly only a few million hectares. However even on million hectares of algae commodities production could have a significant impact on global oil and feed supplies. Assuming a successful R\&D outcome, achievement of an annual productivity of $\sim 100 \mathrm{t} / \mathrm{ha}-\mathrm{y}$ of algal biomass with a high protein and/or oil content, one million hectares of algal ponds would produce as much animal feed as currently grown on the 60 million hectares of U.S. corn and soy crops used for animal feed production, about $10 \%$ of the global trade in animal feeds. Alternatively, one million hectares producing a high oil content algal biomass would produce nearly $1 \%$ of world oil consumption ( $\sim 30$ billion barrels), about the current ethanol production from corn in the USA or from sugar cane in Brazil. However, replacing most fuel or feeds supplies with microalgae, as projected by all too many promoters in this field, is just not credible.

\section{Sustainability of Microalgae Commodities}

Sustainability implies not depleting natural resources or imposing undue environmental impacts, including greenhouse gas emissions, and is a major objective for all renewable technologies. For example, for biofuels a reduction of $70 \%$ in greenhouse gas (GHG) emissions will be required for new renewable energy and fuel sources in the European Union (EU) and California. The determination of whether a particular process meets this requirement is based on a "Life Cycle Assessment" (LCA), which considers the GHG balances from all inputs and outputs to the process, direct and indirect, using established protocols and approved methodologies. A favorable LCA is an essential requirement for any biofuel production process, and will also be needed for animal feeds.

In the past few years over a hundred LCA and related (e.g., net energy analysis) studies of microalgae biofuels have been published. Many, but not all, arrived at favorable conclusions regarding GHG reductions by such processes. Of course, all such studies had to be based on assumptions regarding the production process, engineering designs, biomass and biofuel productivities, harvesting and processing, etc. It is not surprising that these studies not only arrive at very disparate results, but that the scales, designs, inputs, study boundaries, units, processes and LCA methodologies used (such as allocation of co-products) differed so fundamentally between studies as to not allow any direct or useful comparisons [28].

LCAs cannot be based on commercial algae commodities production processes because none exist. Instead LCAs must be based on a projected process that can meet the objective of the LCA, such as a $70 \%$ reduction in GHG emissions compared to conventional fossil fuels. Further, the LCA must also be based on a process for which a techno-economic analysis (TEA) suggests that it can meet the cost objectives of the process. A TEA for algal biofuels that arrives at a cost projection of $\$ 150 /$ barrel oil, would be reasonable, as petroleum are projected at $\$ 100 /$ barrel for the foreseeable future and assuming that renewable fuel would fetch some premium over fossil fuels. However, LCAs based on processes with a TEA projecting much higher costs would not be useful. Thus the value of an LCA, or the associated TEA, is not in the conclusions (e.g., that microalgae biofuels can be produced at acceptable costs and have low GHG emissions), but in the assumptions that form the basis for the TEA, and from which the LCA was then derived. These assumptions must be plausible, and based on known science and engineering, and allow the development of an R\&D plan that could then achieve these objectives. 
Thus, LCAs should not be based on PBRs, use of artificial lights, and other impractical designs, or projections of oil production greatly exceeding 40,000 L/ha-y of algal oil or $100 \mathrm{t} / \mathrm{ha}-\mathrm{y}$ of animal feeds.

A recent LCA by the author and colleagues [28] was based on their earlier TEA [29], which assumed an oil production of 24,000 L/ha-y, and arrived at a relatively high cost of about $\$ 300 /$ barrel of biodiesel. The resulting LCA was favorable, but, clearly, the TEA on which it was based was not. A revised TEA will be required, one that, for example, assumes higher oil productivities, to arrive at more favorable economics for such a process. The objective would be to specify in detail the engineering designs, process assumptions and cost estimates required to achieve such a result. These would then become the basis for specific R\&D objectives, including identification of suitable sites, resource requirements and other constraints. In brief, LCAs and TEAs are tools to help guide R\&D in this field, not prognostications of the future.

\section{Alternative Technologies for Microalgae Biofuels and Feeds Production}

In the above, per force very brief and generic overview, alternative approaches to microalgae biofuels and commodities production were neglected. For example, several projects, spending in aggregate several hundred million dollars and now advancing to the multi-hectare pilot scale, propose to use genetically engineered microalgae that excrete biofuels (ethanol, fatty acids, etc.) into the growth medium. The advantages of such processes are that they would produce little or no algal biomass (except for the initial start-up and some modest replacement culture), and require no harvesting of the biomass, or extraction of the biofuels. However, such processes also require a sterile PBR, as any bacteria present will quickly consume any such excretion products. Developing large sterilizable PBRs would be an even greater achievement than the productivities claimed by most proponents of such processes, which exceed not just practical but often even theoretical limits.

One way to avoid the problem of bacterial contamination is to produce a gaseous product, such as $\mathrm{H}_{2}$, ethylene, etc., which would escape into the gas phase before being consumed by the bacteria. However, after hundreds of millions of dollars and decades of applied algal $\mathrm{H}_{2}$ production $\mathrm{R} \& \mathrm{D}$, the only plausible mechanism that could be the basis an actual process, an indirect biophotolysis process $[11,30]$, has not been yet been convincingly demonstrated even at a laboratory scale.

Another approach to algal biomass production, for either fuels or feeds, are so-called mixotrophic processes, in which organic substrates (acetic acid, sugars, etc.) are added to the algal culture along with photons (e.g., sunlight or artificial illumination) to increase productivity or oil content. Again, such processes can be demonstrated in the laboratory under axenic (bacteria-free) conditions, but would be very challenging with open ponds, or even PBRs. Acetate is used to boost production of Chlorella in commercial systems, but likely only under anaerobic conditions and for short periods. Under aerobic conditions, the $\mathrm{O}_{2}$ generated by photosynthesis, would quickly result in bacteria consuming the organic substrates added.

Other projects aim to grow microalgae attached to surfaces, such as in long flumes, on rotating disks, moving belts, etc. The advantage is that harvesting is minimized, but the practical issues of scale-up of any such process are daunting. Simple attached growth systems do have potential in nutrient removal from very dilute wastewaters, but their applications appear limited in commodities production. 
Finally, the co-cultivation of several algal species mixed as consortia are claimed to have greater stability and productivity than single species cultures. The stable cultivation of single algal species is indeed a major challenge, but managing defined consortia of several species will be even more daunting, and any benefits in feeds or fuels production would be modest, if not illusionary. Mixed cultures are used in wastewater treatment and aquaculture, where they perform a valuable service. In such processes no attempt is made to control algal species, though usually one species dominates ( $>90 \%$ biomass), until replaced by another. It is difficult to understand how such mixed, uncontrolled cultures could be harnessed for production of commodities.

There is no lack of new ideas on microalgae cultivation. But, as detailed above, the ideas on the use of open ponds first proposed decades ago on the mass culture microalgae have stood up rather well and been applied in the commercial production processes developed since for high value nutritional products. The need now is to extend these concepts to lower-cost and larger-scale commodities production, a major challenge indeed.

\section{The Future of Microalgae Fuels and Feeds}

A major R\&D goal in this field is to develop "domesticated" strains of microalgae with a high feed or fuel value that can dominate in the large open, unlined, raceway ponds, with their complex fluctuations in $\mathrm{pH}, \mathrm{O}_{2}$, temperature and light. Dominance means stable cultivation, meaning resistance to invasion by weed algae, grazers, parasitic fungi, viruses, etc. The algal strains thus developed must also be able to be cheaply harvested and processed. A major R\&D effort will be required to develop such strains, tolerant of the pond environment, resistant to biotic challenges, versatile in outputs, and more highly productive than any current agronomic system.

There are grounds for optimism that it may be possible to achieve these goals. As noted earlier, several algal species are already produced commercially in raceway ponds, albeit not many, nor as cheaply or at as large a scale or high productivities as required for fuels and feeds. But some additional species have also been cultivated at relatively large scale. One example is Micractinium (Figure 2h), often dominant in raceway ponds treating wastewaters, and harvested by bioflocculation [15]. Anabaena cylindrica (Figure 2i), a $\mathrm{N}_{2}$ fixing cyanobacterium provides its own nitrogen, a competitive advantage, and such cyanobacteria could be used to co-produce fertilizers and biofuels. Nannochloropsis (Figure 2f) and some diatoms (Figure 2e) can be stably cultivated in open raceway ponds and are the focus of several commercial projects for production of biofuels and nutritional products, in particular because of their content of long chain omega-3 fatty acids. Production of such omega-3 oils for replacement of fish meal and oils is the most promising and nearest-term opportunity for large-scale microalgae commodities production. For the longer-term there is Botryococcus braunii (Figure $2 \mathrm{~g}$ ), which produces up to $50 \%$ of its total weight as hydrocarbons, stored in an extracellular capsule apparently resistant to bacterial degradation and grazing. Although B. braunii grows very slowly, and thus its cultivation has been challenging, it should be possible to develop strains, either by mutation-selection or genetic engineering, that separate growth and hydrocarbon production into distinct phases, making its mass cultivation feasible.

Indeed, strain improvements are essential requirements for microalgal feeds or fuel production. No algal strain isolated from nature ("wild type") will exhibit the desired properties of high 
productivity and high fuel/feed value, as these do not help it survive in nature, or provide an advantage in a raceway pond. The only attribute that can be hoped for in wild-type strains is some resistance to biotic challenges (grazers, infections, etc.). Domestication requires introducing the desired properties into the algal genome, by traditional (mutagenesis, selection) or molecular (genetic engineering) techniques, and, where available, sexual or other genetic recombinations. Seed cultures of such improved strains would then scaled-up (from photobioreactors to enclosed ponds to lined ponds), and massively inoculated into the large unlined production ponds and cultivated for an extended period, for at least a month, before repeating the process. A great deal of R\&D is still required to realize this vision.

Despite their apparent simplicity, microalgae mass cultures are a difficult undertaking and most current R\&D efforts appear to lack a full understanding of the complexities involved, or knowledge of what has already been tried, and all too often failed, before. This brief idiosyncratic overview of this field provides a guide to prior efforts and of the required $R \& D$. Although challenging, there are no apparent insurmountable barriers the production of microalgae commodities for fuels and feeds.

\section{Conflicts of Interest}

The author declares no conflict of interest.

\section{References}

1. Little, A.D. Pilot Plant Studies in the Production of Chlorella. In Algal Culture: From Laboratory to Pilot Plant; Burlew, J.S., Ed.; Carnegie Institution of Washington: Washington, DC, USA, 1953; Chapter 17, pp. 235-273.

2. Oswald, W.J.; Gotaas, H.B. Photosynthesis in sewage treatment. Trans. Am. Soc. Civ. Eng. 1957, 2849, 73-105.

3. Fisher, A.W. Engineering for Algae Culture. In Proceedings of the World Symposium on Applied Solar Energy, Phoenix, AZ, USA, 1-5 November 1955; pp. 243-253.

4. Oswald, W.J.; Golueke, C.G. Biological transformation of solar energy. Sew. Ind. Wastes 1960, $31,1125-1142$.

5. Sheehan, J.; Dunahay, T.; Benemann, J.; Roessler, P.; Weissman, J. Look Back at the U.S. Department of Energy's Aquatic Species Program: Biodiesel from Algae; Close-Out Report for National Renewable Energy Laboratory (NREL): Golden, CO, USA, 1998.

6. Tamiya, H. Mass culture of algae. Annu. Rev. Plant Physiol. 1957, 8, 309-334.

7. Benemann, J.R. Microalgae aquaculture feeds. J. Appl. Phycol. 1992, 4, 233-245.

8. Golueke, C.G.; Oswald, W.J.; Gotaas, H.B. Anaerobic digestion of algae. Appl. Microbiol. 1957, 5, 47-51.

9. Gaffron, H.; Rubin, J. Fermentative and photochemical production of hydrogen in algae. J. Gen. Physiol. 1942, 26, 219-227.

10. Benemann, J.R.; Weare, N.M. Hydrogen evolution by nitrogen-fixing Anabaena cylindrica cultures. Science 1974, 184, 174-175.

11. Benemann, J.R. Hydrogen from microalgae. J. Appl. Phycol. 2000, 12, 291-300. 
12. Huesemann, M.H.; Roesijadi, G.; Benemann, J.; Metting, F.B. Biofuels from Microalgae and Seaweeds. In Biomass to Biofuels: Strategies for Global Industries; Vertès, A.A., Blaschek, H.P., Yukawa, H., Qureshi, N., Eds.; John Wiley and Sons, Inc.: Hoboken, NJ, USA, 2010; pp. 165-184.

13. Weissman, J.C.; Goebel, R.P.; Benemann, J.R. Photobioreactor design: Comparison of open ponds and tubular reactors. Bioeng. Biotech. 1998, 31, 336-344.

14. Benemann, J.R.; Pursoff, P.; Oswald, W.J. Engineering Design and Cost Analysis of a Large-Scale Microalgae Biomass System; NTIS\# HCP/T1605-01 UC-61; Final Report to the U.S. Department of Energy Department: Washington, DC, USA, 1978; pp. 1-91.

15. Benemann, J.R.; Koopman, B.L.; Weissman, J.C.; Eisenberg, D.M.; Goebel, R.P. Development of Microalgae Harvesting and High Rate Pond Technologies in California. In Algae Biomass: Production and Use; Shelef, G., Soeder, C.J., Eds.; Elsevier North Holland Press: Amsterdam, The Netherlands, 1980; pp. 457-496.

16. Benemann, J.R.; Goebel, R.P.; Weissman, J.C.; Augenstein, D.C. Microalgae as a Source of Liquid Fuels; Final Technical Report for US Department of Energy: Washington, DC, USA, 1982.

17. Benemann, J.R.; Oswald, W.J. Systems and Economic Analysis of Microalgae Ponds for Conversion of $\mathrm{CO}_{2}$ to Biomass; Final Report to US Department of Energy, National Energy Technology Laboratory, Pittsburgh, PA, USA, 1996.

18. Kok, B. Experiments on Photosynthesis by Chlorella in Flashing Light. In Algal Culture: From Laboratory to Pilot Plant; Burlew, J.S., Ed.; Carnegie Institution of Washington: Washington, DC, USA, 1953; Chapter 6, pp. 63-76.

19. Kok, B. Photosynthesis. In Proceedings of the Workshop on Bio-solar Conversion, Bethesda, MD, USA, 5-6 September 1973.

20. Benemann, J.R. The Future of Microalgae Biotechnology. In Algal and Cyanobacteria Biotechnology; Cresswell, R.C., Rees, T.A.V., Shah, N., Eds.; Longman Scientific \& Technical: Harlow, UK, 1990; pp. 317-337.

21. Neidhardt, J.; Benemann, J.R.; Baroli, I.; Melis, A. Photosystem-II repair and chloroplast recovery from irradiance stress: Relationship between chronic photoinhibition, light-harvesting chlorophyll antenna size and photosynthetic productivity in Dunaliella salina (green algae). Photosynth. Res. 1998, 56, 175-184.

22. Melis, A.; Neidhardt, J.; Baroli, I.; Benemann, J.R. Maximizing Photosynthetic Productivity and Light Utilization in Microalgae by Minimizing the Light-Harvesting Chlorophyll Antenna Size of the Photosystems. In BioHydrogen; Zaborsky, O.R., Benemann, J.R., Matsunaga, T., Miyake, J., Pietro, A.S., Eds.; Plenum Press: New York, NY, USA, 1998; pp. 41-52.

23. Polle, J.E.W.; Benemann, J.R.; Tanaka, A.; Melis, A. Photosynthetic apparatus organization and function in wild type and a chlorophyll $b$-less mutant of Chlamydomonas reinhardtii. Dependence on carbon source. Planta 2000, 211, 335-344.

24. Polle, J.; Kanakagiri, S.; Benemann, J.R.; Melis, A. Maximizing Photosynthetic Efficiencies and Hydrogen Production by Microalgal Cultures. In Biohydrogen II: An Approach to Environmentally Acceptable Technology; Miyake, J., Matsunanga, T., San Pietro, A., Eds.; Pergamon Press: Oxford, UK, 2001; pp. 111-130. 
25. Huesemann, M.H.; Hausmann, T.S.; Bartha, R.; Aksoy, M.; Weissman, J.C.; Benemann, J.R. Biomass productivities in wild type and pigment mutant of Cyclotella sp. (diatom). App. Biochem. Biotech. 2009, 157, 507-526.

26. Huesemann, M.H.; Benemann, J.R. Biofuels from Microalgae: Review of Products, Processes, and Potential, with Special Focus on Dunaliella sp. In The Alga Dunaliella: Biodiversity, Physiology, Genomics, and Biotechnology; Ben-Amotz, A., Polle, J.E.W., Subba Rao, D.V., Eds.; Science Publishers: New Hampshire, UK, 2009; pp. 445-474.

27. Harder, R.; von Witsch, H. Ueber Massenkultur von Diatomeen. Ber. Dtsch. Bot. Ges. 1942, 60, 146-153 (in German).

28. Benemann, J.R.; Woertz, I.; Lundquist, T. Life cycle assessment for microalgae oil production. Disruptive Sci. Technol. 2012, 1, 68-78.

29. Lundquist, T.; Woertz, I.; Quinn, N.; Benemann, J.R. A Realistic Technology and Engineering Assessment of Algae Biofuel Production; Energy Biosciences Institute: Berkeley, CA, USA, 2010; pp. 1-178.

30. Benemann, J.R. Processes Analysis and Economics of Biophotolysis of Water. A Preliminary Assessment; Report to the International Energy Agency Agreement on the Production and Utilization of Hydrogen: Golden, CO, USA, 1998.

(C) 2013 by the authors; licensee MDPI, Basel, Switzerland. This article is an open access article distributed under the terms and conditions of the Creative Commons Attribution license (http://creativecommons.org/licenses/by/3.0/). 